\title{
sciforum
}

Conference Proceedings Paper

\section{Daily precipitation extremes in isolated and mesoscale precipitation for the southeastern United States}

\author{
Thomas Rickenbach ${ }^{1^{*}}$ \\ Published: 06/11/2017 \\ Academic Editor: Ricardo Trigo \\ 1 Department of Geography, Planning and Environment, East Carolina University, Greenville, North \\ Carolina, USA \\ * Correspondence: rickenbacht@ecu.edu; Tel.: +01-252-328-1039
}

\begin{abstract}
Previous studies of precipitation organization in the southeastern United States demonstrated that a simple framework of precipitation organization was able to capture important differences in the seasonal evolution of mean precipitation produced by isolated convection versus mesoscale precipitation. The goal of the present study is to investigate whether the seasonal change of precipitation intensity, defined as daily precipitation normalized by time raining, and of seasonal maximum precipitation intensity, behave differently with the scale of precipitation organization. A radar-based high resolution precipitation dataset is used to produce daily values of isolated and mesoscale precipitation intensity spanning one year. Precipitation intensity for a one-year period for isolated versus mesoscale precipitation varies seasonally, particularly for isolated precipitation, with the highest precipitation intensities in the summer. However, there is no clear difference with organization in the seasonal maximum daily precipitation intensities, as measured by the seasonal variation in the spatial pattern, and seasonal differences in the pixel-based frequency distribution.
\end{abstract}

Keywords: precipitation intensity; seasonal variation; precipitation organization.

\section{Introduction}

The southeastern United States (SE US) receives consistent year-round precipitation from a variety of weather systems such as mid-latitude cyclones [1,2], tropical cyclones [3,4], sea breeze circulations [5], orographically-enhanced storms [6], and afternoon local storms during summertime [7]. Within those weather systems, precipitation may be organized as small, short-lived and spatially heterogeneous features, hereafter referred to as isolated precipitation features or IPF, or by larger, well-organized and generally longer-lived features, hereafter referred to as mesoscale precipitation features, or MPF [8]. In this context, an isolated thunderstorm is an example of IPF organization, while mesoscale convective systems or widespread frontal rain are examples of MPF organization. A similar framework has been used for climatological studies of precipitation systems regionally and globally using surface and space-based radar observations [8-13]. Differences in the organization of precipitating systems reflect the influence of the large-scale environment, for example, squall line mesoscale convective systems tend to form in environments of high shear and moderate convective available potential energy [14].

A recent climatology of precipitation organization in the SE US demonstrated that this framework of precipitation organization applied to a radar precipitation dataset was able to capture important differences in the seasonal evolution in precipitation organization [8]. The daily accumulated precipitation was averaged for each three-month season to determine whether the 
seasonal cycle differed with precipitation organization. Though MPF precipitation occurred consistently year-round, IPF precipitation showed a dramatic seasonal cycle with a summertime maximum in average daily accumulated precipitation associated with the common occurrence of isolated summertime thunderstorms. This result raised the question of whether or not the rain intensity, defined as daily accumulation normalized by the time of occurrence of daily rain, has a similar seasonal cycle. That is, is the summertime rainfall more intense, and is that intensity stronger or weaker for systems organized on different scales (IPF versus MPF)? Finally, which system type produces the highest daily rain intensity values for each season?

The goal of the present study is to investigate for the SE US the seasonal change of extreme daily precipitation associated with precipitation organization. The approach is to apply the IPF versus MPF framework to the frequency distribution of daily precipitation intensity for a one year period, using a radar-based precipitation dataset with high time and space resolution. The paper examines whether the heaviest daily precipitation values are associated with isolated or mesoscale precipitation organization, and whether this association changes seasonally. Results demonstrate that precipitation intensity for a one-year period for isolated versus mesoscale precipitation varies seasonally, particularly for isolated precipitation, with the highest precipitation intensities in the summer. However, there is no clear difference with organization in the seasonal maximum daily precipitation intensities, as measured by the seasonal variation in the spatial pattern, and seasonal differences in the pixel-based frequency distribution.

\section{Study Design}

The design of this study was to analyze a regional grid of daily precipitation intensity of IPF and MPF precipitation from a one year dataset, and from it determine the seasonal spatial pattern and seasonal frequency distribution of precipitation intensity. The goal was to determine the differences in the seasonal spatial pattern and frequency distribution of precipitation intensity.

The National Mosaic and Multi-sensor Quantitative Precipitation Estimation (NMQ) precipitation dataset [15], based on the National Weather Service national radar network, was the basis for the analysis in this study. Data from the a $1 \mathrm{~km} \times 1 \mathrm{~km}$ national grid, including pixels in the coastal region up to $150 \mathrm{~km}$ offshore, were extracted over the SE US for the year 2011. This domain is shown in Figure 1.

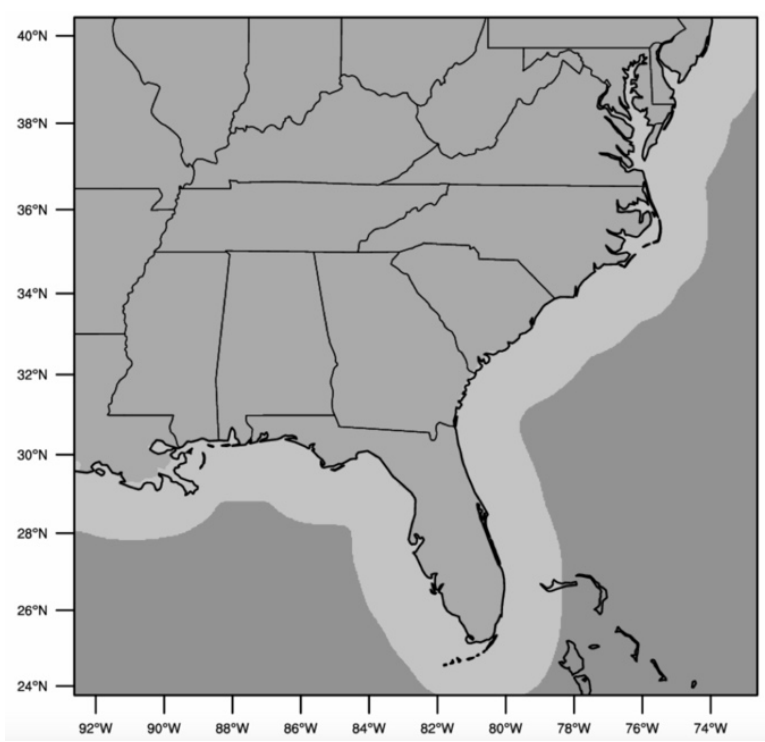

Figure 1. NMQ precipitation data domain across the southeastern United States. The light gray region shows the offshore extent of the dataset. No data is available in the dark gray region over the ocean. 
The 1st International Electronic Conference on Hydrological Cycle (CHyCle-2017), 12 - 16 November 2017; Sciforum Electronic Conference Series, Vol. 1, 2017

An algorithm to identify IPF and MPF precipitation features, where MPF are identified as features $100 \mathrm{~km}$ or greater in maximum horizontal dimension and all smaller features identified as IPF, was applied for each 15 minute grid, averaged daily, and compiled for the entire year following the methodology described in our recent study [8]. The complete dataset will be available at an online archive prior to publication. Grids of daily-averaged precipitation intensity, defined at each pixel as the daily accumulation divided by the time precipitation was present $\left(>0.5 \mathrm{~mm} \mathrm{hr}{ }^{-1}\right)$, were constructed for each day of 2011. Three-month seasonally-averaged precipitation intensity was composited for IPF and MPF pixels from the daily precipitation intensity data. Similarly, grids were constructed of the maximum daily precipitation intensity, defined as the maximum value of daily precipitation intensity for each season at each pixel, for IPF and MPF. The frequency distribution of maximum daily precipitation intensity was then determined for each season for IPF and MPF pixels.

\section{Results}

Daily-averaged values of precipitation intensity (hereafter 'precipitation intensity') associated with IPF and MPF organization in the SE US were averaged seasonally for winter (December, January, February), spring (March, April, May), summer (June, July, August) and autumn (September, October, November). These are contrasted with maps of the maximum value of daily precipitation intensity occurring over each season (hereafter 'maximum precipitation intensity') at each pixel for IPF and MPF, along with a histogram of the seasonal cycle of spatially-integrated maximum precipitation intensity. Finally, the frequency distribution of all pixels of each seasonal map of maximum precipitation intensity is presented.

\subsection{Seasonal cycle of precipitation intensity}

Shown below are maps of the seasonal variation of precipitation intensity for IPF (Figure 2) and for MPF (Figure 3). The IPF precipitation intensity has a strong seasonal cycle, with a clear summer maximum and winter minimum. In spring, IPF precipitation intensity builds in south Florida and in the Ohio Valley north of the Appalachian mountains, as well as in the mid-Atlantic region and offshore of the Carolinas. By summer, the Florida peninsula has the highest IPF intensity, as well as the coastal plain of the Atlantic and Gulf region. In autumn the IPF intensity has ramped down but remains highest offshore, in the relatively warm waters associated with the Gulf Stream. The MPF precipitation intensity has a less dramatic seasonal cycle, with precipitation across the domain year round but slightly higher peak intensities in the summer. The most extensive MPF precipitation occurs in spring in the northeastern domain, where baroclinic systems are most actively producing widespread precipitation [2,8]. The seasonal cycle of domain-averaged precipitation intensity for IPF and MPF (Figure 4) shows that in the winter and spring, MPF has 50\% - 60\% higher values than IPF, while in summer IPF slightly exceeds MPF by about $5 \%$.

These trends are generally similar to a previously published four-year IPF and MPF precipitation climatology of daily-averaged accumulation [8], which focused on the averaged total daily accumulated precipitation rather than precipitation intensity. The MPF annual cycle of precipitation intensity shown herein has a larger seasonal change and a more heterogeneous spatial pattern than the the daily accumulated precipitation, suggesting that MPF precipitation intensity likely responds more to the seasonal cycle of thermodynamically generated instability. This is clearly the case for IPF precipitation intensity, as well as for IPF daily accumulated precipitation. 
The 1st International Electronic Conference on Hydrological Cycle (CHyCle-2017), 12 - 16 November 2017; Sciforum Electronic Conference Series, Vol. 1, 2017

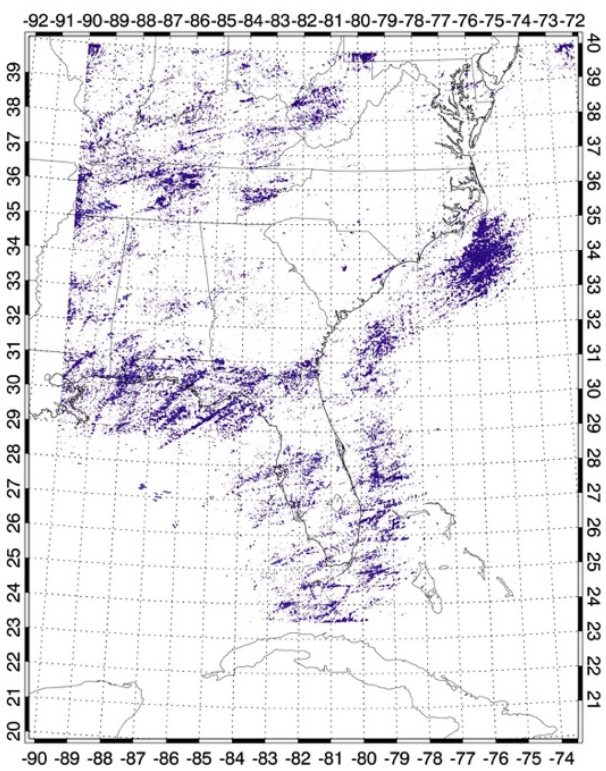

(a)

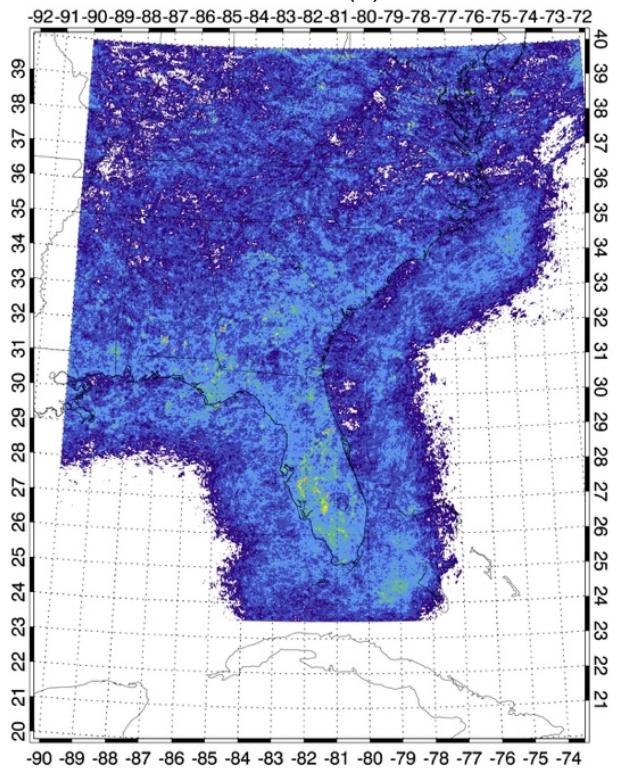

(c)

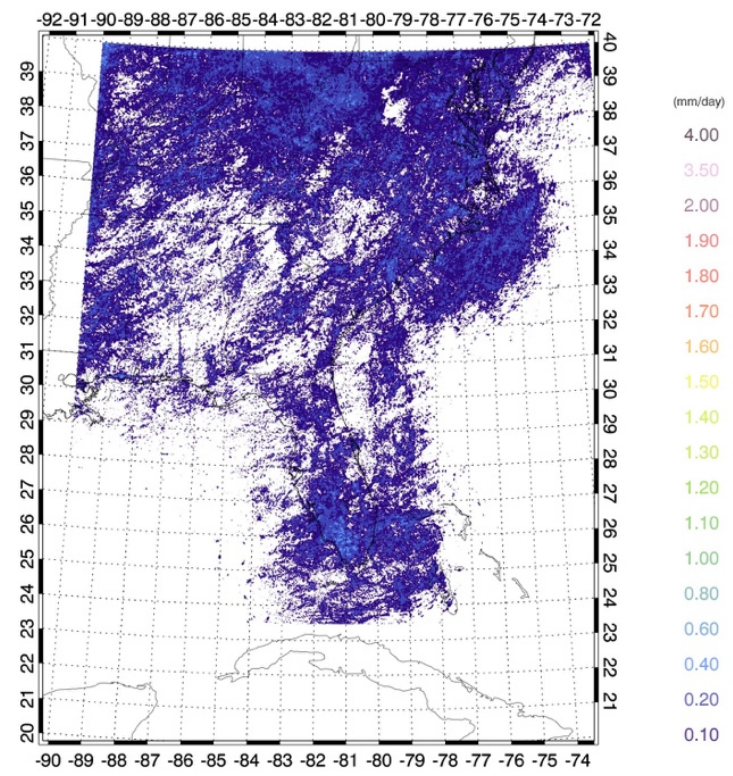

(b)

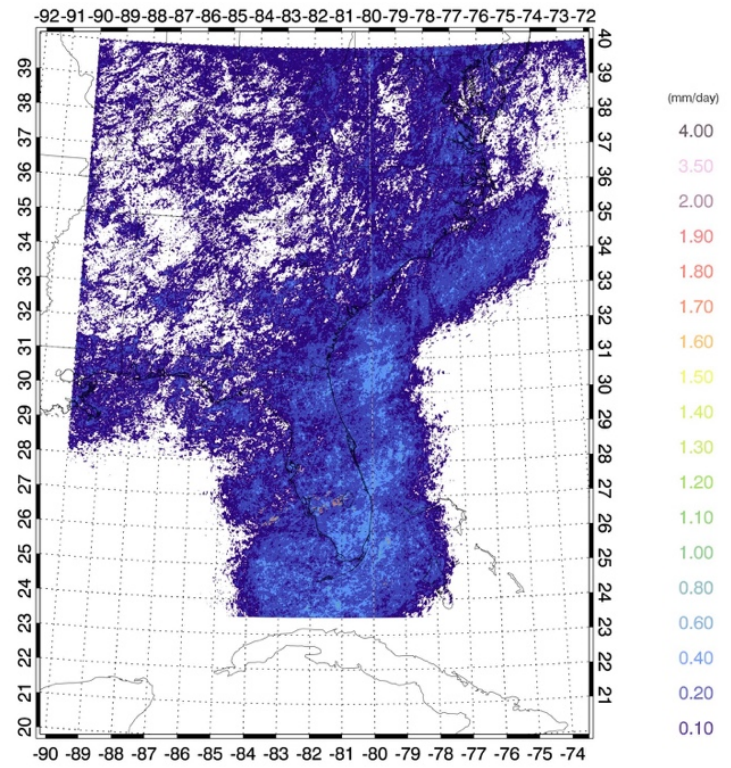

(d)

Figure 2. Seasonal maps of IPF precipitation intensity (as defined in the text) for: (a) Winter (DJF); (b) Spring (MAM); (c) Summer (JJA); (d) Autumn (SON). 
The 1st International Electronic Conference on Hydrological Cycle (CHyCle-2017), 12 - 16 November 2017; Sciforum Electronic Conference Series, Vol. 1, 2017

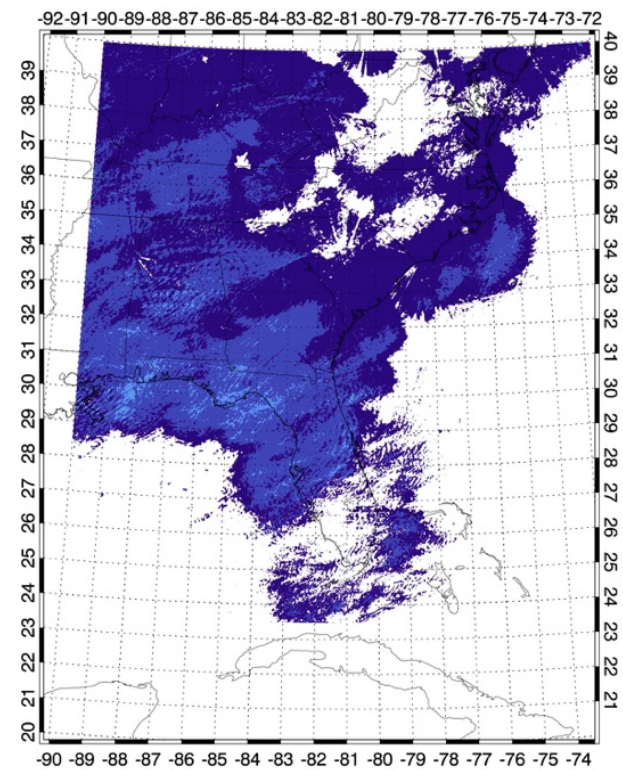

(a)

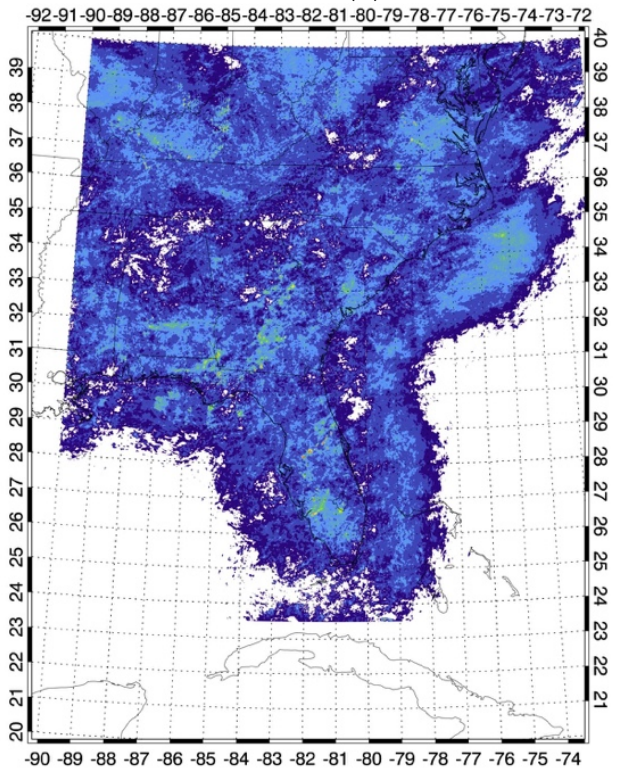

(c)

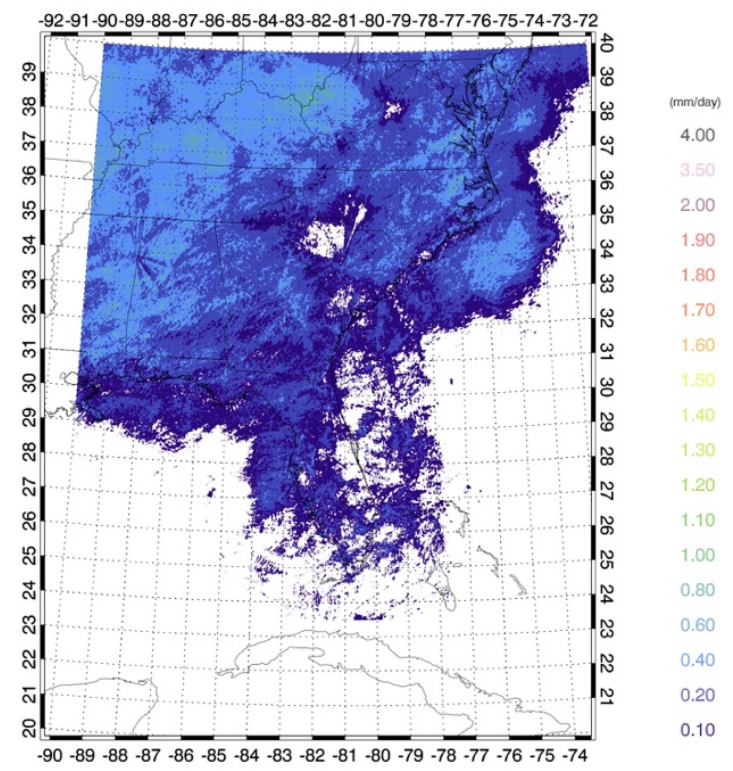

(b)

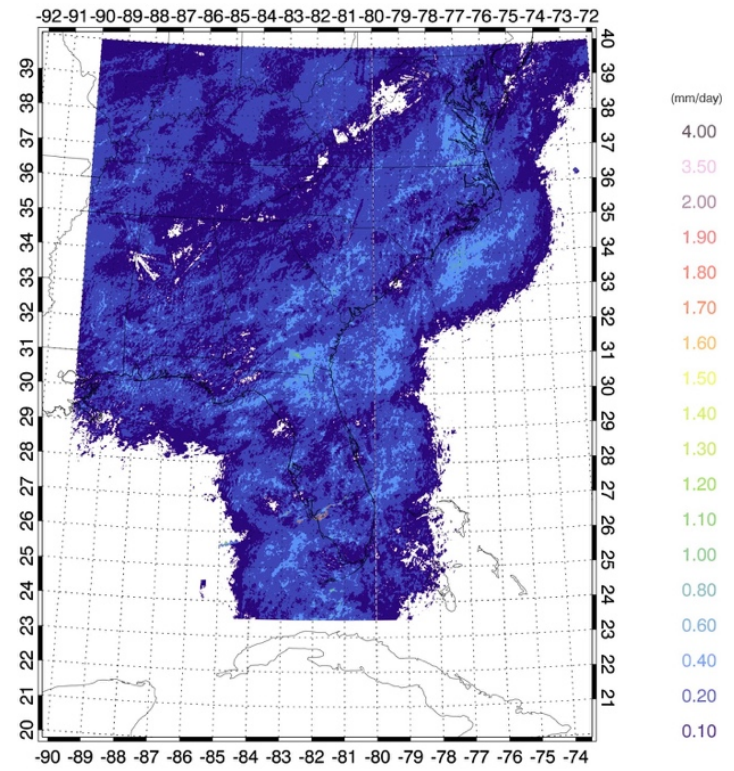

(d)

Figure 3. Seasonal maps of MPF precipitation intensity (as defined in the text) for: (a) Winter (DJF); (b) Spring (MAM); (c) Summer (JJA); (d) Autumn (SON). 


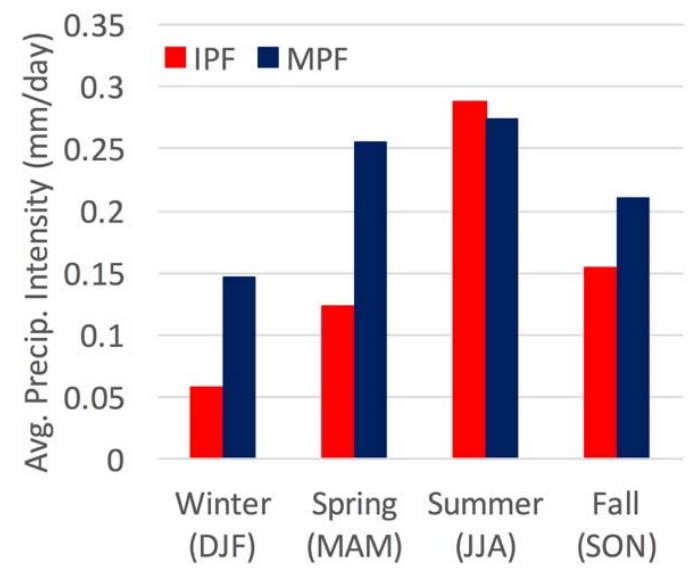

Figure 4. Seasonal variation of domain-averaged precipitation intensity for IPF and MPF.

\subsection{Seasonal cycle of maximum precipitation intensity}

The seasonal change in maximum precipitation intensity, defined as the maximum value of daily precipitation for each season at each pixel, is shown for IPF (Figure 5) and MPF (Figure 6). These maps indicate the spatial pattern of the maximum value of daily precipitation intensity that occurred each season. As such the pattern is much 'grainier' than the averaged daily precipitation intensity (Figures 4-5) since these maxima may reflect several individual events with locally high precipitation intensity. For IPF, maxima are weak and concentrated in south Florida, while summer maxima are widespread across the domain though most intense in the coastal plain and Florida panhandle. For $\mathrm{MPF}$, the peak values are more heterogeneous, with a spatial pattern in the summer suggesting the intense rain maxima may have been associated with one or two events. This inference is consistent with the occurrence of several strong squall line mesoscale convective systems that propagated eastward in the Ohio Valley (northern domain) and across Georgia (southern domain in the coastal plain). As for averaged precipitation intensity, the pattern of MPF maximum intensity has a weaker seasonal variation than for IPF. This suggests that MPF can produce heavy precipitation year round, though concentrated more to the southern latitudes in the winter season.

The seasonal cycle of the domain-averaged maximum precipitation intensity for IPF and MPF is given in Figure 7. It is quite similar to the domain-averaged daily mean precipitation intensity (Figure 4). The main difference is that for spring, summer and fall, Figure 7 suggests that IPF and MPF maximum intensity are closer to each other than in Figure 4, suggesting that the processes that generally drive intensity maxima (likely thermodynamic) operate similarly on strong convection in both IPF and MPF systems. 
The 1st International Electronic Conference on Hydrological Cycle (CHyCle-2017), 12 - 16 November 2017; Sciforum Electronic Conference Series, Vol. 1, 2017

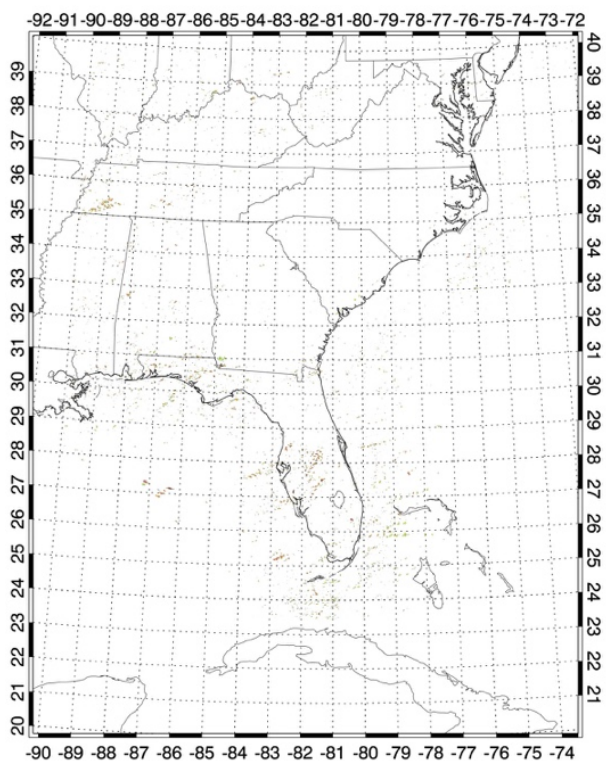

(a)

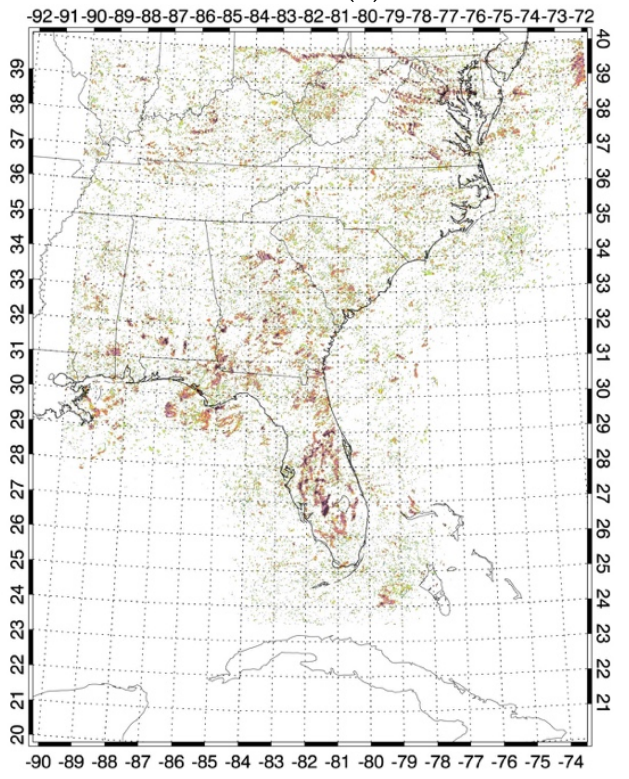

(c)

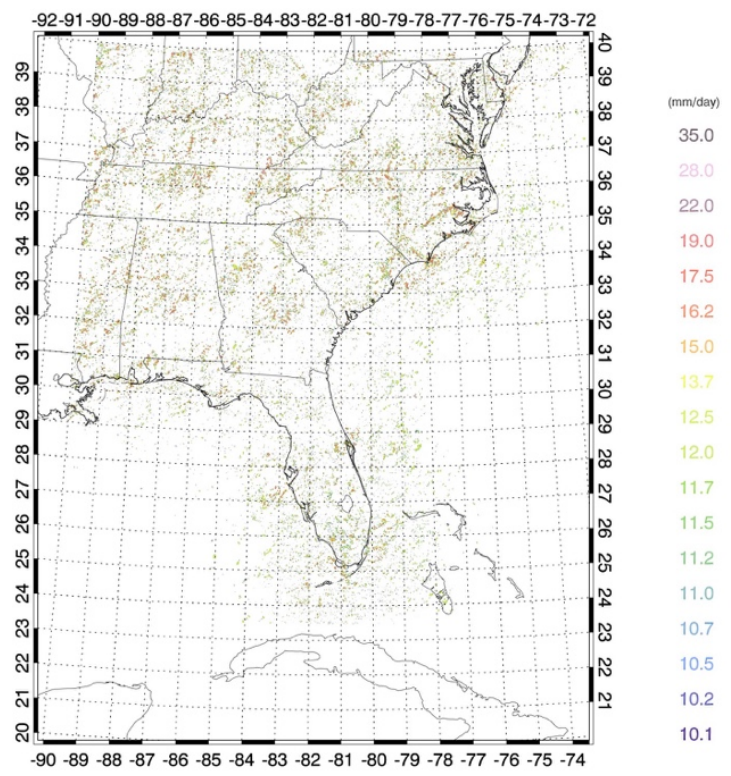

(b)

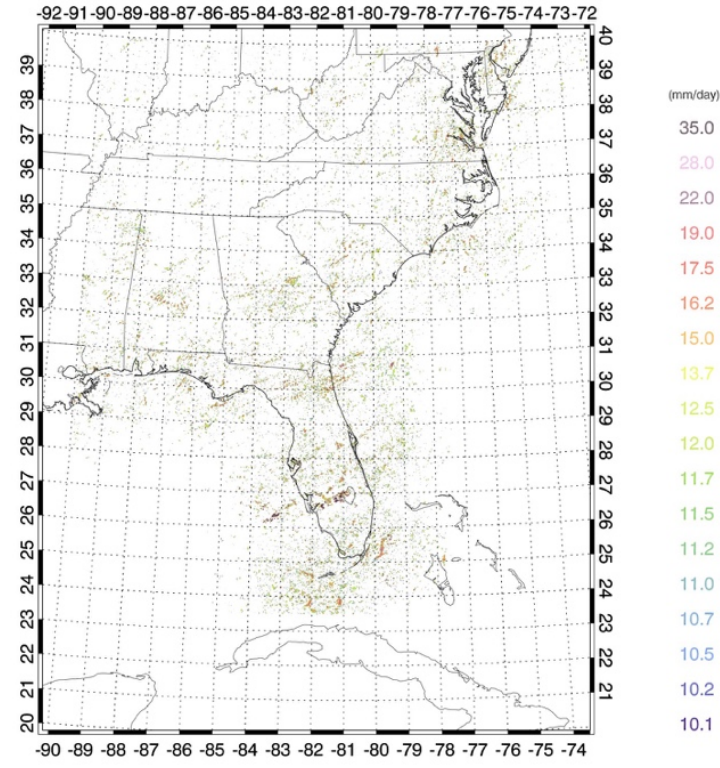

(d)

Figure 5. Seasonal maps of IPF maximum precipitation intensity (as defined in the text) for: (a) Winter (DJF); (b) Spring (MAM); (c) Summer (JJA); (d) Autumn (SON). 
The 1st International Electronic Conference on Hydrological Cycle (CHyCle-2017), 12 - 16 November 2017; Sciforum Electronic Conference Series, Vol. 1, 2017

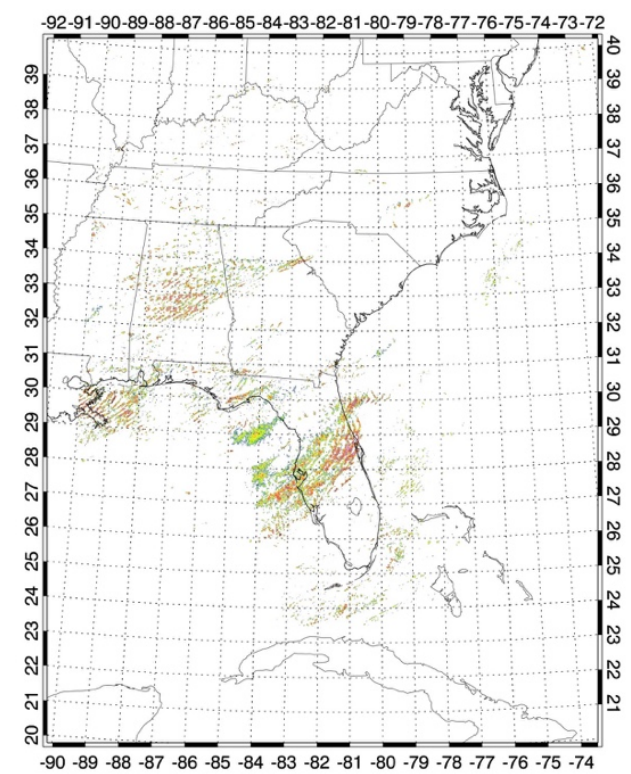

(a)

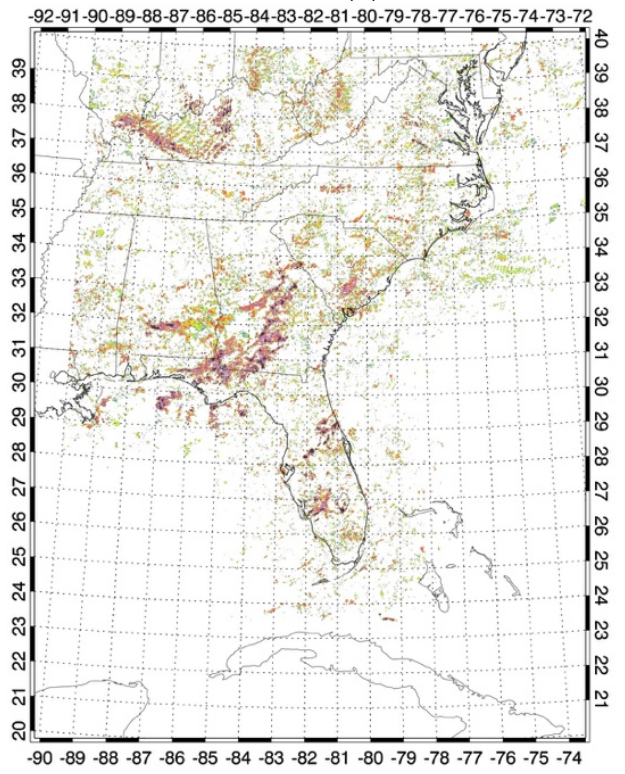

(c)

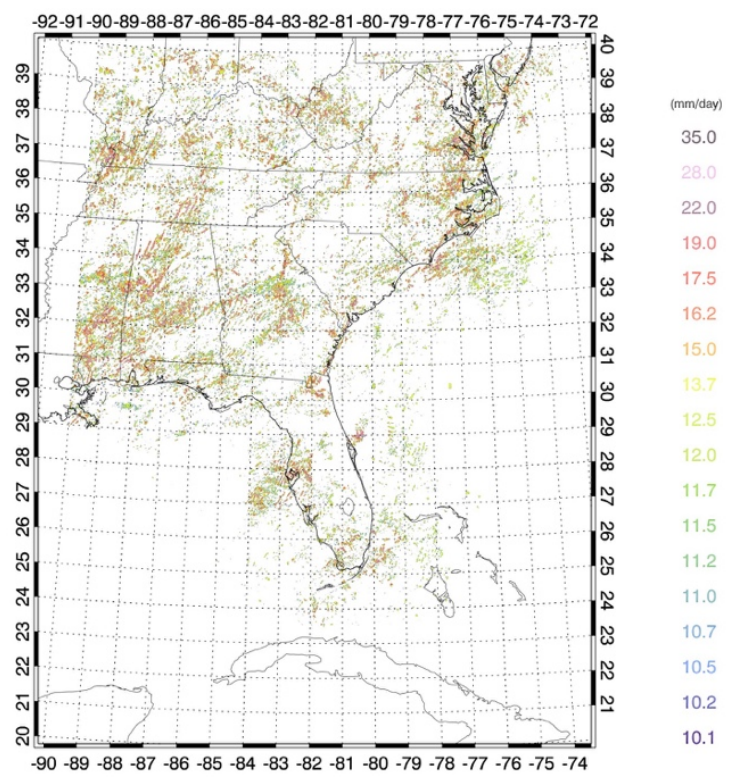

(b)

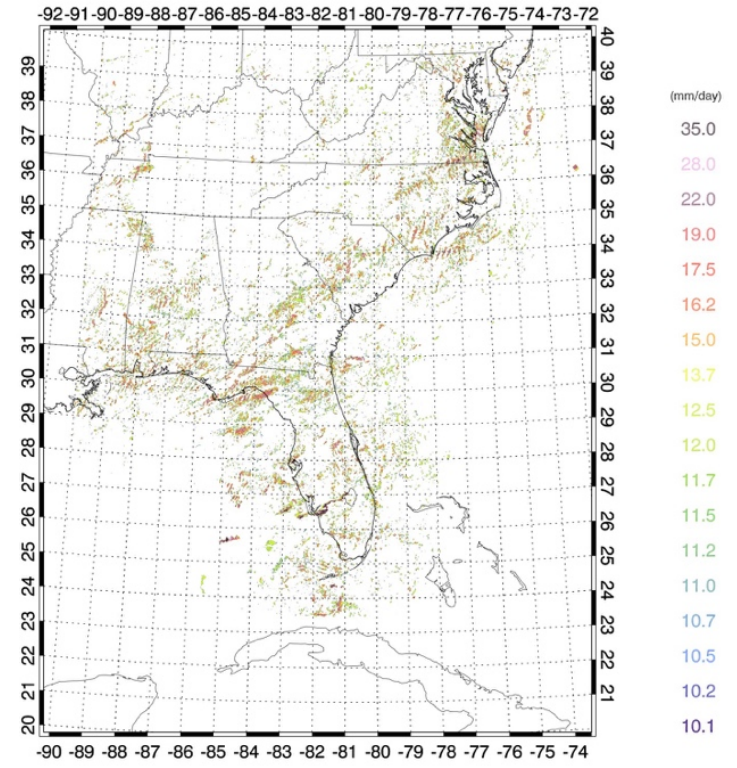

(d)

Figure 6. Seasonal maps of MPF maximum precipitation intensity (as defined in the text) for: (a) Winter (DJF); (b) Spring (MAM); (c) Summer (JJA); (d) Autumn (SON). 
The 1st International Electronic Conference on Hydrological Cycle (CHyCle-2017), 12 - 16 November 2017; Sciforum Electronic Conference Series, Vol. 1, 2017

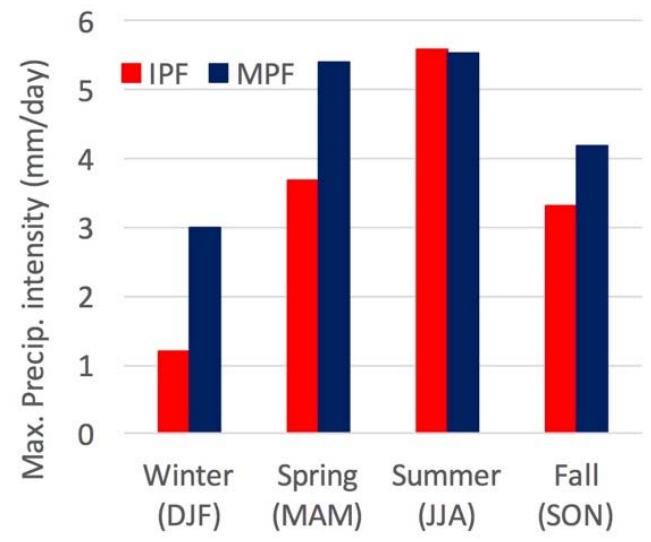

Figure 7. Seasonal variation of domain-averaged maximum precipitation intensity for IPF and MPF.

\subsection{Frequency distribution of seasonal maximum precipitation intensity}

In order to examine more closely the occurrence of extreme values in the seasonal cycle of maximum precipitation intensity for IPF and MPF, the frequency distribution of maximum intensity pixels for each season is presented in Figure 8. The distributions show the relative frequency of occurrence of maximum precipitation intensity values in $0.5 \mathrm{~mm}^{\text {day }}{ }^{-1}$ bins. For all seasons and both system types, the well-established behavior is evident of an exponential decrease in the frequency of precipitation pixels of increasing intensity. That is, weaker maximum precipitation intensity is much more common. In all seasons except for summer, MPF pixels are more common for a given precipitation intensity value, which is qualitatively evident in the spatial maps of Figure 5 and 6 . At the higher intensities, in all seasons IPF and MPF show a similar range of frequencies for maximum precipitation intensity above about $30 \mathrm{~mm}^{\text {day }}{ }^{-1}$. This suggests that the physical processes that produce the highest values of maximum precipitation intensity are similar for IPF and MPF (likely thermodynamic).

Figure 8 shows that above $30 \mathrm{~mm}$ day $^{-1}$ the frequencies appear more variable, since because there are so few pixels at that intensity small changes in pixel count lead to relatively large frequency variation. However, MPF frequencies are more variable compared to IPF as intensity increases above $30 \mathrm{~mm}$ day $^{-1}$. The cause of the MPF versus IPF difference is not clear, but may be related to MPF events being more episodic and variable in occurrence compared to IPF. Interestingly, in spring (MAM) the frequency of maximum precipitation intensity above about $32 \mathrm{~mm}^{-1 a y^{-1}}$ for both IPF and MPF drops rapidly to zero above $40 \mathrm{~mm}$ day- $^{-1}$, except for a lone low frequency of $55 \mathrm{~mm}^{\text {day }}{ }^{-1}$ for IPF. In all other seasons, maximum precipitation intensity values remain at low frequency through $60 \mathrm{~mm} \mathrm{day}^{-1}$. The reason for this behavior in spring may be related to the spring transition from winter baroclinic forcing to summer thermodynamic forcing, perhaps resulting in a spring minimum of the heaviest precipitation intensities.

\section{Discussion}

The SE US has a wide variety of synoptic precipitation regimes. Previous work has demonstrated a strong seasonality to the occurrence of baroclinic systems and thermodynamically driven diurnal isolated storms. A simple framework of precipitation organization, mesoscale versus isolated precipitation features (MPF and IPF), has been shown previously to capture important differences in diurnal and seasonal variation of precipitation with respect to the scale of precipitation organization. 
The 1st International Electronic Conference on Hydrological Cycle (CHyCle-2017), 12 - 16 November 2017; Sciforum Electronic Conference Series, Vol. 1, 2017
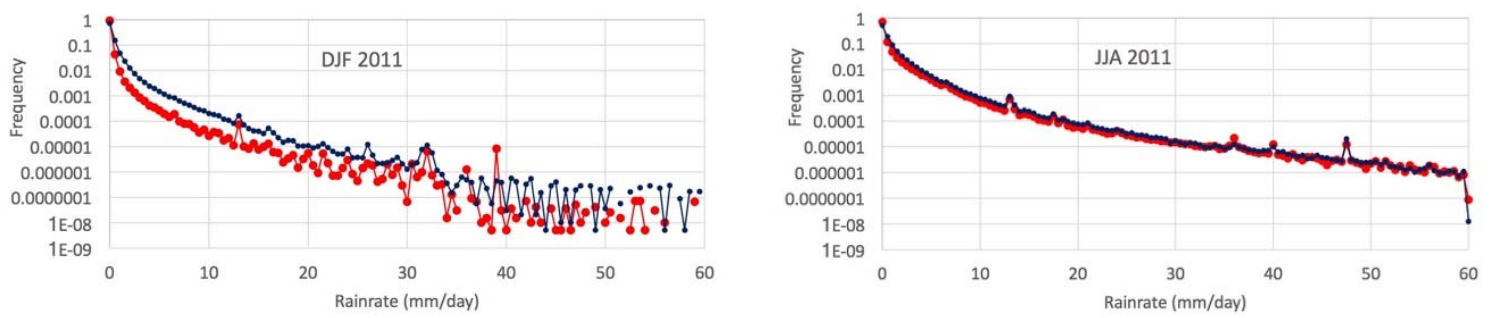

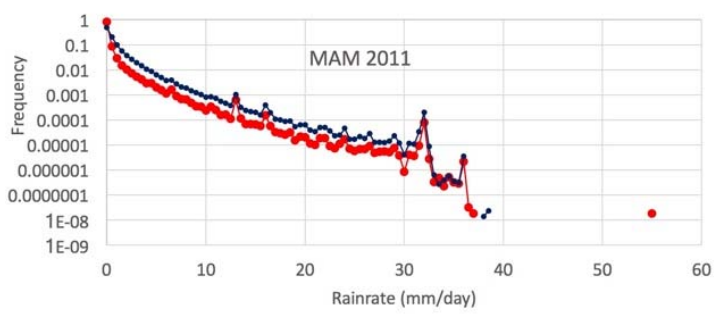

(a)

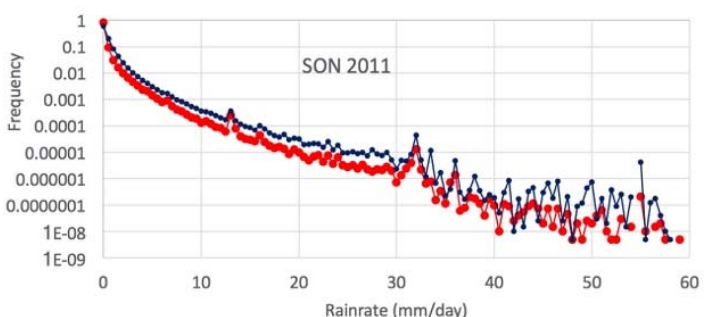

(b)

Figure 8. Frequency distribution of maximum precipitation intensity pixels for IPF (red) and MPF (dark blue), from the seasonal maps shown in Figures 5 and 6, for: (a) Winter (DJF), upper panel and Spring (MAM), lower panel; (b) Summer (JJA), upper panel and Autumn (SON), lower panel.

The present study examined the hypothesis that the spatial pattern and frequency distribution of precipitation intensity are distinct for MPF and IPF organization. Results from a preliminary analysis of precipitation intensity (daily rain accumulation normalized by time raining) spanning one year reveal distinct seasonal patterns, with a strong summer maximum in IPF with a somewhat weaker seasonal cycle in MPF. A further examination of the spatial pattern and frequency distribution of the seasonal average of daily maximum precipitation intensity revealed less of a distinction in IPF and MPF precipitation than expected from previous results.

This study suggests the hypothesis that the mechanisms generating maximum precipitation intensity occur similarly in both IPF and MPF precipitation, implying that thermodynamic mechanisms common to both organization categories (ample moisture and instability), rather than larger scale dynamical forcing, likely controls locally high precipitation intensity. This preliminary result is broadly consistent with the idea that extreme precipitation intensity is controlled by the broad thermodynamic base state rather than changes in precipitation organization. This result has implications for studies examining mechanisms that control extreme precipitation change as the Earth warms.

Future work will expand this preliminary one-year study to a fifteen year period to improve robustness of this result.

\section{Conclusions}

The main findings from the study are as follows. Precipitation intensity for a one-year period for isolated versus mesoscale precipitation organization (IPF and MPF) in the southeastern United States varies seasonally, particularly for IPF, with the highest precipitation intensities in the summer. However, there is no clear difference in the seasonal maximum daily precipitation intensities for IPF versus MPF, as measured by the seasonal variation in the spatial pattern, and seasonal differences in the pixel-based frequency distribution. 
The 1st International Electronic Conference on Hydrological Cycle (CHyCle-2017), 12 - 16 November 2017; Sciforum Electronic Conference Series, Vol. 1, 2017

Acknowledgments: This study was funded by grants (AGS-1118141 and AGS-1660049) from the Climate and Large-Scale Dynamics program and the Physical and Dynamic Meteorology program in the Division of Atmospheric and Geospatial Science of the National Science Foundation (United States).

Conflicts of Interest: The authors declare no conflict of interest. The founding sponsors had no role in the design of the study; in the collection, analyses, or interpretation of data; in the writing of the manuscript, and in the decision to publish the results.

\section{Abbreviations}

The following abbreviations are used in this manuscript:

SE US: Southeastern United States

IPF: isolated precipitation feature

MPF: mesoscale precipitation feature

DJF: December, January, February (winter)

MAM: March, April, May (spring)

JJA: June, July, August (summer)

SON: September, October, November (autumn)

NMQ: National Mosaic and Multi-sensor Quantitative Precipitation Estimation (NMQ) precipitation dataset

\section{References}

1. Curtis, S., 2006. Developing a climatology of the South's 'other' storm season: ENSO impacts on winter extratropical cyclogenesis. Southeastern Geographer, 2006, 46(2), 231-244.

2. Nieto Ferreira, R., Hall, L., Rickenbach, T. A climatology of the structure, evolution and propagation of midlatitude cyclones in the southeast United States. J. Climate, 2013, 26, 8406-8421.

3. Larson, J., Zhou, Y., Higgins, R.W. Characteristics of landfalling tropical cyclones in the United States and Mexico: Climatology and interannual variability. J. Climate, 2005, 18(8), 1247-1262.

4. Shepherd, J. M., Grundstein, A., Mote, T. Quantifying the contribution of tropical cyclones to extreme rainfall along the coastal southeastern United States. Geophysical Research Letters, 2007, 34, L23810, doi:10.1029/2007GL031694.

5. Koch, S. and Ray, C. Mesoanalysis of summertime convergence zones in central and eastern North Carolina. Weather and Forecasting, 1997, 12, 56-77.

6. Parker, M.D., Ahijevych, D.A. Convective episodes in the east-central United States. Monthly Weather Review, 2007, 135, 3707-3727.

7. Winkler, J.A., Skeeter, B.R., Yamamoto, P.D. Seasonal variations in the diurnal characteristics of heavy hourly precipitation across the United States. Monthly Weather Review, 1988, 116(8),1641-1658.

8. Rickenbach, T.M., Nieto-Ferreira, R., Zarzar, C., Nelson, B. A seasonal and diurnal climatology of precipitation organization in the southeastern United States. Q. J. Roy. Met. Soc., 2015, 141, 1938-1956, doi:10.1002/qj2500.

9. Rickenbach, T. M., Rutledge, S.A. Convection in TOGA COARE: Horizontal scale, morphology and rainfall production. Journal of the Atmospheric Sciences, 1998, 55, 2715-2729.

10. Nesbitt, S.W., Zipser, E.J., Cecil, D.J. A census of precipitation features in the tropics using TRMM: Radar, ice scattering, and lightning observations. Journal of Climate, 2000, 13(23), 4087-4106.

11. Nesbitt, S.W., Cifelli, R., Rutledge, S.A., Storm morphology and rainfall characteristics of TRMM precipitation features. Monthly Weather Review, 2006, 134, 2702-2721.

12. Rickenbach, T.M., Nieto-Ferreira, R., Barnhill, R., Nesbitt, S. Regional contrast of mesoscale convective system structure prior to and during monsoon onset across South America. Journal of Climate, 2011, 24, 3753-3763. 
The 1st International Electronic Conference on Hydrological Cycle (CHyCle-2017), 12 - 16 November 2017;

Sciforum Electronic Conference Series, Vol. 1, 2017

13. Rickenbach, T.M., Nieto-Ferreira, R., Barnhill, R., Nesbitt, S. Seasonal and regional differences in the rainfall and intensity of isolated convection over South America. International Journal of Climatology, 2013, 33, 2002-2007.

14. Keenan, T.D., Carbone, R.E., A preliminary morphology of precipitation systems in tropical northern Australia. Quarterly Journal of the Royal Meteorological Society, 1992, 118(504), 283-326.

15. Zhang, J., Howard, K., Vasiloff, S., Langston, C., Kaney, B., Arthur, A., Van Cooten, S., Kelleher, K., Kitzmiller, D., F. Ding, F. National Mosaic and QPE (NMQ) System: description, results, and future plans. Bull. Am. Met. Soc., 2011, 92, 1321-1338.

(C) 2017 by the authors; licensee MDPI, Basel, Switzerland. This article is an open access article distributed under the terms and conditions of the Creative Commons by Attribution (CC-BY) license (http://creativecommons.org/licenses/by/4.0/). 